\title{
Relações interpessoais e trocas dialógicas na execução penal de metodologia alternativa
}

\author{
Relaciones interpersonales e intercambios dialógicos en la ejecución penal de \\ metodología alternativa \\ Interpersonal Relations and Dialogical Exchanges at the flternative Penal Institution
}

\author{
Sirlene Lopes de Miranda* \\ Universidad de São Paulo \\ Danilo Silva Guimarães** \\ Universidad de São Paulo
}

Doi: http://dx.doi.org/10.12804/revistas.urosario.edu.co/apl/a.7877

\section{Resumo}

O objetivo desse artigo é discutir conflitos dialógicos vivenciados por homens privados de liberdade em um sistema prisional no qual a pessoa assume dupla posição: cumpre sua pena, mas participa da administração da instituição penal, como responsável pela segurança. É um dos resultados de uma pesquisa qualitativa, que consistiu em um estudo de caso no método alternativo de cumprimento de pena privativa de liberdade. Discutiremos aqui, seletivamente, resultados de um percurso de 12 visitas à instituição para observar como se davam as relações interpessoais, com registro das informações em um diário de campo, e entrevistas com 18 pessoas, perante consentimento prévio. Do convívio entre os homens privados de liberdade, bem como do compartilhamento de experiências alegres e tristes no contexto institucionalizado, emergiu um campo de mútua afetação, trocas dialógicas e afetivo-cognitivas relevantes à construção do Self. Como o compartilha- mento intersubjetivo nunca é pleno, a pesquisa nos permitiu compreender como a pessoas podem conduzir seu curso de ação em direção a um afastamento pessoal nas relações interpessoais e institucionais, fortalecendo atitudes autorreflexivas não verbalizadas.

Palavras-chave: psicologia dialógica, conflitos dialógicos, relações interpessoais, sistema prisional alternativo.

\section{Resumen}

El objetivo de este artículo es discutir conflictos dialógicos vividos por hombres privados de la libertad en un sistema carcelario en el cual la persona asume una doble posición: cumple su pena, pero participa de la administración de la institución penal, como responsable por la seguridad. En uno de los resultados de una investigación cualitativa, que consistió en un estudio de caso en el método alternativo de cumplimiento de pena privativa de la liberta. Discutiremos aquí, selectivamente, resultados de un recorrido de 12 visitas a la institución para

* Dirigir correspondencia a Sirlene Lopes de Miranda Universidad de São Paulo. Correio eletrônico: sirlene.miranda@hotmail.com ** Universidad de São Paulo.

Para citar este artigo: Miranda, S.L. \&; Guimarães, S. D. (2019). Relações interpessoais e trocas dialógicas na execução penal de metodologia alternativa. Avances en Psicología Latinoamericana, 36(2), 235-251. Doi: http://dx.doi.org/10.12804/ revistas.urosario.edu.co/apl/a.7877 
observar cómo se daban las relaciones interpersonales, con registro de las informaciones en un diario de campo, y entrevistas con 18 personas, ante consentimiento previo. De la convivencia entre los hombres privados de la libertad, así como del compartir de experiencias alegres y tristes en el contexto institucionalizado, emergió un campo de mutua afectación, intercambios dialógicos y afectivo-cognitivos relevantes a la construcción del Self. Como el compartir intersubjetivo nunca es pleno, la investigación nos permitió comprender como las personas pueden conducir su curso de acción en dirección a un distanciamiento personal en las relaciones interpersonales e institucionales, fortaleciendo actitudes auto-reflexivas no verbalizadas.

Palabras clave: psicología dialógica, conflictos dialógicos, relaciones interpersonales, sistema carcelario alternativo.

\section{fbstract}

The aim of this article is to discuss dialogical conflicts experienced by men deprived of their freedom in a prison system in which the person assumes a dual position: he fulfills his sentence but participates in the administration of the penal institution as responsible for security. It is one of the results of a qualitative research, which consisted of a case study an alternative method of serving a custodial sentence. We will here selectively discuss the results of 12 visits to the institution to observe how interpersonal relationships tended to occur; information were recorded in a field diary, and interviews with 18 people were carried out with prior consent. From the interactions of the institutionalized men, in which they shared joyful and sad experiences in the institutional context, emerged a field of mutual affect, dialogical and affective-cognitive exchanges relevant to the construction of the Self. Because intersubjective sharing is never complete, the research allowed us to understand how people can conduct the course of their action towards a personal separation regarding interpersonal and institutional relationships, and strengthening more nonverbal self-reflexive attitudes.
Keywords: Dialogic psychology, dialogic conflicts, interpersonal relations, alternative penal institution.

O objetivo deste artigo é discutir os conflitos dialógicos vivenciados por homens privados de liberdade em um sistema prisional no qual a pessoa assume dupla posição: cumpre sua pena, mas participa da administração da instituição penal, como responsável pela segurança. Partimos da seguinte pergunta: Que sentidos as pessoas atribuem às relações institucionais e interpessoais que constroem no fluxo da experiência prisional?

$\mathrm{O}$ artigo apresenta e discute resultados de uma pesquisa qualitativa, que consistiu em um estudo de caso na Associação de Proteção e Assistência os Condenados (APAC), em uma unidade deste sistema prisional alternativo, que prescinde de presença policial. Trata-se de um percurso de 12 visitas à instituição para observar como se davam as relações interpessoais, com registro das informações em um diário de campo, e entrevistas com 18 pessoas, perante consentimento prévio.

A abordagem teórico-metodológica selecionada para o estudo se situa no campo da psicologia cultural, em sua vertente semiótico-construtivista, uma perspectiva de pesquisa que emergiu a partir dos estudos sobre os sentidos presentes nas relações eu-outro-mundo significativas (Simão, 2016, p. xi). Aárea se dedica, dentre outros temas, a compreender as relações que se dão entre: o eu e o outro em um mundo sensível; os aspectos intra e intersubjetivos constitutivos da pessoa e as negociações e trocas dialógicas que tomam parte nesse processo. Discutiremos, ao longo do artigo, como os tensionamentos provocados pela participação institucional, incluindo a aplicação de sanções, guiam a elaboração que as pessoas que participam da APAC fazem de suas experiências prévias e atuais, contribuindo para o desenvolvimento do Self. 


\section{Relações institucionais na metodologia alternativa de execução penal}

Os conflitos interpessoais e intrapessoais vivenciados em um contexto fortemente institucionalizado podem favorecer um distanciamento entre posições pessoais e institucionais durante a execução penal, o que implica em uma tensão ou desencaixe entre expectativas e experiência institucionalizada. Antes de adentrar à APAC (instituição prisional que será descrita com mais detalhes no tópico metodologia), as pessoas em aprisionamento cumprem pena no presídio estadual (execução penal convencional) e consegue mudança de instituição perante solicitação e aprovação prévia do juiz da execução penal. Assim, portanto, carregam suas experiências subjetivas conforme as relações ali estabelecidas. No sistema alternativo de execução penal, novas relações interpessoais são construídas, regras disciplinares são implementadas e atividades laborais diárias são distribuídas entre as pessoas, conforme regime de cumprimento de pena, aptidões e interesses profissionais (Ferreira, 2016). Assim, é possível que esse contato com o outro, também enquanto outro método de cumprimento de pena, favoreça, desde a entrada da pessoa na instituição APAC, uma imersão em novas propostas de construção de sentidos a respeito de si, sua pena, seu futuro, sua família, suas possibilidades, o que, possivelmente, promove conflitos nas relações interpessoais estabelecidas e entre as múltiplas perspectivas socioculturais presentes no campo institucional.

Quando a pessoa se defronta com novos sistemas de valores (Branco \& Madureira, 2008), o sistema de valoração atualmente adotado pode ser questionado a partir de novas experiências e significados que emergem em um contexto relacional e institucional diferente. Comer com talheres, cozinhar o próprio alimento, ter acesso ao pátio durante todo o dia, mesmo no regime fechado, autorização para receber visita de familiares de segundo grau, sem revistas vexatórias, praticar atividades físicas, ter atendimento jurídico, psicológico, atividades profissionalizantes e ensino fundamental, médio e superior à distância, a partir de uma disciplina rigorosa que regula as relações interpessoais nos regimes e demarca um cumprimento severo dos horários de atividades terapêuticas, tudo isto, coloca em questão as regras que foram construídas anteriormente no presídio.

Interesses coletivos e pessoais também geram conflitos nas relações intra e interpessoais. O método APAC de execução penal prevê a participação de algumas pessoas em cumprimento de pena no Conselho de Sinceridade e Solidariedade (CSS), um conselho que visa auxiliar a diretoria no cumprimento da disciplina e na aplicabilidade das penalidades às pessoas em cumprimento de pena que descumprirem as regras estabelecidas (o que acarreta perda de benefícios, como saídas temporárias). O papel exercido por esse Conselho propicia tensionamentos entre as pessoas em cumprimento de pena para cada respectivo regime, fechado, semiaberto e aberto, pois ao mesmo tempo em que convivem no mesmo regime, também precisam repassar informações sobre seus colegas para a administração e, na ausência dos funcionários, aplicar as próprias advertências diante das faltas leves e medianas de seus colegas de dormitório. As faltas graves são comunicadas pelo CSS ao administrativo da instituição. Em caso de faltas leves, em geral, ocorre advertência verbal aplicada pelo presidente do CSS. Nas faltas médias, as pessoas em cumprimento de pena podem perder benefícios como visita íntima, e ter uma redução dos dias de saída temporária. As faltas graves são comunicadas pelo setor administrativo da instituição ao Judiciário e caberá ao juiz da execução a aplicabilidade das penalidades, que, em geral, referem-se ao retorno definitivo ou temporário (como medida cautelar) para o sistema convencional, bem como a uma regressão de regime (Ottoboni, 1997/2001; Ferreira, 2016).

A instituição define papéis assimétricos entre os interlocutores, o que produz conflitos entre as posições pessoais e papéis institucionais que, por 
sua vez, balizam a emergência de tensões nas relações institucionais na APAC. ${ }^{1}$ Sendo esta experiência institucionalizada permeada por tensões dialógicas (Marková, 2006), a instituição participa do processo de construção cultural do Self das pessoas, ao restringir e/ou favorecer possibilidades de ação e desenvolvimento do Self durante a experiência neste contexto.

\section{Intersubjetividade e coautoria na vida institucionalizada}

Considerando que a subjetividade se constrói na interação com o outro em um mundo sensível, como este outro participa da internalização dos aspectos constitutivos do eu? Os processos de subjetivação serão analisados aqui a partir de uma compreensão de desenvolvimento do Self, dos posicionamentos pessoais que as pessoas assumem perante os outros e o mundo, os quais se expressam por meio de enunciados. Nesse ensejo, uma das principais vias de desenvolvimento humano ocorre através da busca do sujeito pelo compartilhamento de experiências com as outras pessoas, ou seja, pela busca de intersubjetividade (Guimarães \& Simão, 2007).

Para Rommetveit (1979), a procura pelo compartilhamento intersubjetivo demanda esforço e descentração do sujeito, um desprendimento para compreensão do outro levado à cabo por ambas as pessoas em relação. A partir do esforço por uma descentração podem surgir rupturas, trocas dialógicas, mudanças de posicionamentos e reelaborações de sentidos a respeito de si, do outro e do mundo. Porém, para que a intersubjetividade possa emergir nas relações é preciso um campo de negociações de sentidos da experiência compartilhada entre o eu e o outro, entre os participantes de uma interação social que se esforcem em buscar esse compartilhamento, ainda que seja um partilhar mínimo e

A noção de baliza utilizada nesse texto refere-se a um constructo teórico de Valsiner (1998) e as tensões dialógicas vêm de Marková (2006). temporário conjunto de experiências, dado que não há compartilhamento pleno de experiências no fluxo das relações eu-outro.

A persistência em manter uma relação com compartilhamentos de experiência remete à noção de alteridade na experiência intersubjetiva em que o outro sempre apresenta algo que lhe escapa e excede na relação. Simão (2010) discute a noção de alteridade como a disponibilidade de alguém para o envolvimento com o diferente de si mesmo, um processo que pode ser carregado de tensão, não apenas pelas diferenças que o eu e o outro possam perceber entre si, mas pela impossibilidade de se ter acesso completo a esse outro no contexto da relação. Assim, pode surgir um estranhamento nas relações eu-outro, diferenças e distanciamentos nessas relações. A relação eu-outro, aqui proposta, envolve compreender um processo psicológico de construção de sentidos em coautoria, e desse modo, será sempre iniciante, provisória, variando em suas diversas circunstâncias de acontecimento (Simão, 2010).

A partir de Marková (2003), podemos compreender que há um estranhamento nas relações eu-outro que promove tensões dialógicas, uma tensão que não pertence a um ou outro interlocutor, mas à relação no diálogo. Marková (2003) argumenta que a dialogicidade deve ser entendida como coautoria em vez de intersubjetividade, dado que emerge como uma forma de compreensão da construção da subjetividade a partir de uma relação com o outro que não é possível abarcar. "Seres humanos fazem o mundo nos termos dos outros, e a existência inteira do self é orientada na direção da linguagem dos outros e do mundo dos outros" (Marková, 2003, p. 256). Ela recorre à noção de Bakhtin quanto à coautoria, pela qual se compreende que a vida é preenchida e orientada pela existência dos outros, e esse viver no mundo dos outros é compreendido como coautoria.

A noção de dialogicidade também tem sido utilizada para se refletir sobre processos intrapessoais. A proposta de Herman, Kempen e van Loon (1991) 
concebe o mundo interno compreendido como um mundo social imaginado e composto por vozes de múltiplos autores sociais. As relações eu-outro-mundo, por sua vez, são específicas e singulares. A partir delas cada pessoa passa a significar o mundo, em que as experiências sempre novas, em uma temporalidade irreversível, demandam reposicionamentos pessoais ao lidar com as tensões dialógicas emergentes. A assimetria no diálogo promove, por sua vez, experiências inquietantes às pessoas. As experiências inquietantes,

\section{[...] criam instabilidade, tensão, perturbam ou} mesmo ferem as expectativas da pessoa sobre a habilidade de entender a si mesmo e às suas relações Eu-Outro-Mundo, instigando a pessoa a sentir, pensar e agir de modo cognitivo e afetivo, em diferentes direções daquelas que ela estava seguindo até então, de tal modo que a pessoa pode chegar a integrar sentimentos despertados por ela em sua base afetivo-cognitiva, que, por sua vez também mudará. (Simão, Guimarães, Freitas, Bastos \& Sanchez, 2015, p. 7)

Os processos de elaboração afetivo-cognitiva das experiências inquietantes articulam percepções e imaginações: no curso de vida da pessoa, "percepção e imaginação relacionam-se dialeticamente, então, grande parte de nossa abordagem perceptiva do exterior é desenvolvida por nossas elaborações internas imaginativas e vice-versa" (Guimarães, 2013, p. 224). Guimarães entende que o desenvolvimento da pessoa envolve recursos simbólicos (Zittoun, 2006) pessoais e ações articuladas pela compreensão perceptiva e imaginária do Self. Ao tomarmos as concepções de recursos simbólicos e ações simbólicas em um campo cultural (Boesch, 1991), concebemos que os processos intersubjetivos não dizem respeito, apenas, ao que se dá na interação entre duas ou mais pessoas, mas também entre diferentes níveis intrapessoais do Self.

\section{Metodologia}

A metodologia empregada neste estudo visou compreender as relações interpessoais e tensões dialógicas que emergem a partir de uma vivência institucionalizada de cumprimento de pena. No processo dialógico de construção do conhecimento, participantes e pesquisador atuam efetivamente em conjunto na construção de um novo conhecimento, e a pesquisa se dá em um campo de ação simbólica, em que pesquisador e participantes negociam sentidos, fazendo emergir tensões no diálogo sobre o fenômeno estudado (Simão, 1988/1989; Simão et al., 2015).

A participação observante (Bastien, 2007; Malfitano \& Marques, 2011) foi o ponto de partida do processo de observação, viabilizando a vivência de relações interpessoais concretas no contexto institucional e a posterior realização de entrevistas semiestruturadas com os participantes. Nessa proposta metodológica, consideramos que pesquisador está, primeiro, na condição de participante coconstrutor do fenômeno estudado. É porque faz parte do contexto, ainda que, temporariamente, realiza uma observação. Já "o observador participante, em contraponto, é o pesquisador que vai ao campo para realizar uma investigação. Seu objetivo não é a participação, mas a observação" (Malfitano \& Marques, 2011, p. 290). A pesquisadora, ainda, priorizou, em sua proposta investigativa, a participação pública, em detrimento da observação distanciada, ao acompanhar e colaborar com as atividades rotineiras da instituição.

Os dados foram construídos segundo uma abordagem dialógica, que pressupõe uma relação pesquisador-participante na qual o conhecimento se constitui a partir de trocas, tensões e negociações dialógicas nas experiências sensíveis na relação eu-outro-mundo (Simão, 2010; Simão et al., 2015). Na construção dos dados, a pesquisadora produziu um diário de campo para registro das informações levantadas durante a observação no contexto institucional. A partir dos dados empíricos construídos 
no contexto institucional, a seleção do conteúdo para a discussão foi realizada partindo-se da noção de campo-tema (Spink, 2003). Campo-tema diz respeito às redes de sentidos que se interconectam, "é um espaço criado [...] herdado ou incorporado pelo pesquisador ou pesquisadora e negociado na medida em que este busca se inserir nas suas teias de ação" (Spink, 2003, p. 28). O campo é concebido como uma rede de sentidos construídos a partir das trocas dialógicas sobre o tema de estudo. Desse modo, tanto o diário de campo quanto as entrevistas realizadas com os participantes da pesquisa foram considerados como vozes em tensão presentes no campo-tema da execução penal alternativa proposta pela APAC.

Dezoito pessoas foram entrevistadas no processo de pesquisa, perante consentimento livre e esclarecido, sendo uma pessoa em cumprimento de pena de cada regime (fechado, semiaberto e aberto); duas pessoas em cumprimento de pena, membros do Conselho de Sinceridade e Solidariedade (CSS) regimes fechado e semiaberto (totalizando cinco pessoas em cumprimento de pena); juíza da vara de execução penal; e duas pessoas para cada uma das demais categorias que compõem a instituição APAC: funcionários; membros da diretoria; voluntários; familiares das pessoas em cumprimento de pena; egressos do método APAC; e membros da Fraternidade Brasileira de Assistência aos Condenados- (FBAC).

Foram identificadas e analisadas as antinomias e aspectos expressivos (Marková, 2006) presentes em cada campo-tema selecionado, a partir de um protocolo de análise dialógica (Wertsch, 1993). Para a análise, utilizamos uma estratégia que destaca a situação concreta extraverbal e a articulação dos movimentos analítico e interpretativo na construção de uma pesquisa (Guimarães, 2016).

\section{Características da instituição abordada}

A APAC foi fundada em 1972, em São José dos Campos/SP. Pessoas integrantes do Cursilho de
Cristandade da Igreja Católica de São Paulo/SP que realizavam visitas periódicas às pessoas em cumprimento de pena - inquietas com os problemas relacionados aos direitos humanos, à carência de assistência psicossocial e de saúde aos presos e à superlotação das celas nesse presídio - desenvolveram um projeto piloto baseado em um conjunto de atividades de intervenção e assistência à pessoa em cumprimento de pena (Ottoboni, 1997/2001). Na ocasião, estas atividades eram conhecidas como "Amando ao Próximo, Amarás a Cristo", origem da sigla APAC, que se alterou, posteriormente, para Associação, quando aprovada como pessoa jurídica, em respeito ao aspecto laico do Estado previsto no artigo 19 da Constituição Federal de 1988. Esse mesmo grupo de pessoas assumiu a direção da Cadeia Pública de Humaitá, que se transformou em 1974 em pessoa jurídica de direito privado e uma organização sem fins lucrativos, adotando, a partir de então, a denominação "Associação de Proteção e Assistência aos Condenados - APAC" (Ottoboni, 1997/2001).

Ressaltamos que a metodologia penal APAC diz de um conjunto de cerca de 80 unidades prisionais no Brasil. O estudo foi realizado em uma delas, sendo preservada sua identificação. A escolha por uma APAC do interior de Minas Gerais para sediar a pesquisa deve-se à experiência preliminar de um dos pesquisadores com esta instituição (em sua fundação), ao canalizar análises que considerem elementos extraverbais a partir das relações concretas no âmbito institucional, no contexto de uma pesquisa que parte de uma perspectiva dialógica. Sua pertinência deve-se ao estudo priorizar uma unidade prisional em processo intermédio de construção: existe um convênio de manutenção aprovado e em vigor pelo TJMG, porém, há o interesse em expandir a assistência para mais de 45 pessoas. Esse processo intermédio se refere a uma instituição que contempla os três regimes de execução penal, mas que inclui um número pequeno de pessoas em cumprimento de pena, devido à fase de transição e construção. 
Atualmente, a unidade da APAC possui 45 pessoas em cumprimento de penas, sendo 22 em regime fechado, 19 em regime semiaberto e quatro em regime aberto. Em sua estrutura administrativa, a APAC possui 13 funcionários, sendo cinco assistentes (financeiro e administrativo), cinco inspetores de segurança, um gerente administrativo, um motorista e uma estagiária jurídica. Conta, também, com dez voluntários que, após participação em cursos de formação de voluntários, oferecido pela própria instituição, assumem atividades regulares.

Nosso interesse em uma unidade prisional em processo intermediário de desenvolvimento se justifica teórico-metodologicamente, uma vez que a situação de transição ENTRE o que é e o que se espera ser, se constitui como um campo fértil para a emergência de antinomias, questionamentos, inquietações e conflitos nas assimetrias dialógicas, na medida em que as rotinas institucionais estariam menos sedimentadas.

\section{Resultados e discussão}

A seguir, apresentaremos, inicialmente, tensões dialógicas, antinomias e aspectos expressivos que emergiram nas relações interpessoais no contexto penal APAC. Salientamos que os resultados discutidos aqui referem-se a um recorte seletivo meio a um conjunto amplo de dados construídos, visando atender aos objetivos propostos para o artigo. Partimos do conteúdo dos enunciados das entrevistas e dos dados extraverbais registrados do diário de campo.

Foram identificadas, desse material, oito antinomias no campo-tema relações interpessoais, sendo elas: (1) o trabalho como oportunidade de remição de pena e profissionalização versus o trabalho como castigo; (2) a religião como atribuição de sentido para a vida versus a religião como invasão da privacidade; (3) a colaboração e o compartilhamento de experiências entre as pessoas que cumprem pena versus relação interpessoal conflitiva no cotidiano institucional; (4) seguir as normas da instituição versus seguir as regras do convívio do próprio dormitório; (5) ser membro do Css versus ser uma pessoa que cumpre pena; (6) o desejo de estar próximo dos familiares nas visitas e eventos versus medos e receios quanto a não ser aceito por esses familiares ao assumir que está preso; (7) distanciamento afetivo-familiar versus manutenção de relações afetivas durante a pena; e (8) ser membro do grupo de pessoas que cumprem pena versus colocar-se como membro do grupo dos egressos, para os quais as regras e preceitos legais perdem efeito.

Sintetizamos essas antinomias em três 'antinomias-tema': (1) colaboração e compartilhamento de experiências versus conflitos interpessoais e afastamentos nas relações; (2) contribuição com o método de execução penal versus preocupação consigo e com sua redução de pena; e (3) posições pessoais versus posições institucionais. Essas antinomias-tema nos permitiram compreender tensões dialógicas que sugerem compartilhamento de experiências na relação eu-outro ou afastamento interpessoal, nos aproximando de questões relativas à colaboração e aos conflitos nas relações interpessoais no contexto institucional APAC.

\section{Tensões nas relações interpessoais: compartilhamento de experiências versus afastamento interpessoal}

No contexto institucional APAC, verificamos que a assimetria nas relações interpessoais e entre posições pessoais e institucionais tomam espaço conjuntamente com as negociações interpessoais e trocas dialógicas estabelecidas com as diferentes perspectivas socioculturais que permeiam a execução penal e favorecem a interpelação do Self da pessoa por antinomias e inquietações. As assimetrias no diálogo institucional são mantidas pelas relações de poder que inibem ou silenciam certas vozes no contexto relacional APAC, como a pessoa que precisa se submeter à disciplina para se manter na instituição ou o funcionário que cumpre preceitos institucionais 
ainda que não concorde com eles. Consequentemente, esses membros institucionais são confrontados em suas posições pessoais por esses aspectos presentes na APAC. Recorro ao enunciado do encarregado de segurança para ilustrar esses aspectos.

Pesquisadora: E como são as relações entre vocês aqui dentro de um modo geral, funcionários e recuperandos? Como você vê essa relação?

Entrevistado: A gente tem que ser ao mesmo tempo um pouco diferente, a gente com eles e eles com a gente. Ao mesmo tempo que a gente vê eles como pessoas que precisam de ajuda a gente vê que são pessoas também que precisa que a gente puxe a orelha, quando for preciso...que a gente precisa saber dar um não na hora que precisa. Um ir e vir. (Comunicação pessoal, 25/10/15)

A respeito da relação entre os funcionários e os homens em aprisionamento, o encarregado de segurança e dois outros funcionários descreveram como "um ir e vir", ora aconselhar, ora aplicar penalidades, semelhante ao discurso do inspetor de segurança que relatou a necessidade de ora aproximação, ora distanciamento, ora ser acolhedor, ora expressar mais uma posição de autoridade em seu comportamento. Percebemos um deslocamento fluido entre as posições pessoais e institucionais, ora compartilhamento de experiência no contexto institucional, ora um afastamento interpessoal para aplicar as penalidades disciplinares. O Self é, desse modo, guiado por dois enquadramentos simultâneos ${ }^{2}$ (Moore, Jasper \& Gillespie, 2011) que o favorece experimentar tensões que emergem entre esses enquadramentos.

O contexto institucional APAC oferece possibilidades de ação, mas também limites para a pessoa que cumpre pena e demais membros, principalmen-

2 Os enquadramentos (Moore, Jasper \& Gillespie, 2011) dizem de aspectos diferentes e simultâneos que podem favorecer dilemas, algo essencialmente dialógico e que se coloca na interseção entre cognição e vida social. te ao delimitar posições assimétricas nas funções institucionais. A pessoa, ao agir afetivamente e cognitivamente, constrói seus significados, sendo que esses podem ser compartilhados com outras pessoas, construindo-se assim uma cultura coletiva (Valsiner, 2012). Essa, por sua vez, guiará futuramente as atitudes da pessoa, ao limitar ou oferecer oportunidade para ação dessa pessoa em seu contexto de interações sociais e trocas simbólicas. Ao estabelecer possibilidades para a pessoa, a instituição norteia as atitudes dela a partir da constituição de objetivos e planos de execução da ação em uma ou outra direção no futuro. Assim, as posições institucionais, para além de se constituírem limites de ação para o membro institucional na APAC, também balizam o potencial de ação (Boesch, 1991) dessa pessoa sobre a própria cultura institucional, ao reconstruí-la, bem como canaliza novas alternativas de ação para si e para as demais pessoas na APAC, através das mudanças de perspectivas, de atividades e de planejamentos institucionais.

Esses aspectos nos permitem refletir sobre o enunciado do encarregado e os aspectos extraverbais das relações concretas percebidas durante o estudo de caso e que explicitaram os seguintes aspectos expressivos: comprometimento com a instituição APAC; tristeza e decepção em relação ao comportamento da pessoa que, desrespeitando as normas e regras disciplinares, recebe uma penalidade; angústia e ansiedade diante de seus papéis institucionais; alegria em acompanhar o término de cumprimento de pena das pessoas; sentimento de culpa nas ocasiões em que algum colega de dormitório retorna ao presídio por cometer faltas graves; e expectativas ora feridas, ora surpreendidas na relação com as pessoas que cumprem pena.

\section{Tensões nas relações interpessoais no contexto institucional: colaboração versus conflitos interpessoais}

A metodologia APAC de execução penal pressupõe colaboração e auxílio entre as pessoas, 
'recuperando ajudando recuperando', no que diz respeito ao cumprimento da metodologia penal, bem como pela promoção e cuidado com a saúde física e psíquica das pessoas durante a pena, ao assegurar os direitos previstos pela Lei de Execução Penal. Entretanto, essa colaboração, por vezes, também perde espaço para os conflitos que se mantém, em especial, na aplicação das regras disciplinares pelos membros do CSS em cada regime.

O presidente do CSS do regime semiaberto (com cerca de oito meses de experiência nessa função na data da entrevista) relatou conflitos entre seus interesses pessoais e os papéis a ele atribuídos enquanto presidente do CSS. Afirmou que, ao encontrar um colega de regime a cometer falta grave, aplica uma advertência verbal em até três situações seguidas. Na quarta vez que ocorre aquela mesma falta, segundo ele, já procura o setor administrativo e informa o ocorrido. Disse que antes de comunicar oficialmente a falta, avisa a própria pessoa que terá de comunicar sua indisciplina e, que, consequentemente, ela será punida. As penalidades incluem perdas de benefícios, progressão de regime e até mesmo, em casos de uso de drogas,

perda do direito de permanecer na APAC. Entretanto, conforme relatado por ele, quando essas faltas ocorrem, o conselho disciplinar ou o próprio judiciário (em caso de faltas graves) determina quais penalidades serão cabíveis para cada circunstância. Nas próximas ocorrências de faltas, ele descreveu vivenciar conflitos com os colegas por tê-los delatado anteriormente. Isso implica uma posição conflitiva para o Self, uma vez que precisa seguir regras, aplicar advertências aos colegas de dormitório e comunicar as faltas graves, o que poderá, consequentemente, impedir a permanência de alguns de seus colegas no próprio sistema prisional APAC.

Trazemos abaixo um fragmento da entrevista com esse presidente do CSS da instituição APAC que exemplifica as relações interpessoais entre as pessoas que cumprem pena no método APAC.
Pesquisadora: E entre os recuperandos, como é a convivência? Você por ser do Conselho -CSS, algumas vezes já aconteceu de ter que intervir?

Entrevistado: Tem. Às vezes, tem intriga... tem bate boca, tem recuperando que não dá certo com o outro, então eles ficam naquela assim... a Fulano é caguete (delator) [...] [sic] então ele começa a bater boca e a gente pede pra parar, entra no meio, porque aqui não pode ter discussão... [...] Porque a gente não dá certo, nem mesmo irmão, imagine então você colocar um monte de preso juntos, cada um com uma personalidade, cada um com uma cabeça diferente, cada um com um vínculo social completamente diferente, então, é complicado. É difícil conviver ... Igual eu sempre falo, não é ruim ir para a cadeia. O mais difícil na cadeia é a convivência, você aturar certas pessoas, ter que conviver com preso. O difícil é isso sim aqui na APAC.

Pesquisadora: Já houve alguma situação na reunião prisional em que você precisou intervir?

Entrevistado: A gente tenta resolver, mas na maioria das reuniões tem bate boca. Alguns ali ficam batendo boca [...]. Então, eles querem que, quando o administrativo não está aqui, que vire bagunça, que isso aqui corra solto. Eles querem assistir televisão quando não pode, eles querem tomar banho o dia todo, ficar debaixo do chuveiro uma hora com chuveiro ligado. E, aí, você vai cobrar, eles acham ruim. [...] É difícil!!!. (Comunicação pessoal, 23/08/15)

Em síntese, o interesse em contribuir para a APAC conflita com o papel a ser desempenhado como presidente do CSS, bem como com suas expectativas feridas dentro do próprio método e seus interesses pessoais, um aspecto que produz inquietações. Assim, as relações eu-outro no campo institucional APAC, a partir do relato desse entrevistado, definem tensões entre demandas institucionais e expectativas pessoais. Ao se sentir desconfortável com o papel de presidente do CSS, a pessoa pode também se aproximar ou se distanciar dessas 
funções e atribuições, numa convivência carregada de tensões interpessoais que também favorecem um campo expressivo tênue e controverso em suas relações institucionais, e promovem a dúvida entre permanecer ou sair desse papel.

Destacamos alguns aspectos expressivos na narrativa do participante: investimento afetivo na instituição APAC apesar das decepções e angústias no cotidiano institucional e no cumprimento das regras e normas disciplinares; descrever-se como desrespeitado pelos demais ao desempenhar sua função de presidente do CSS, o que sugere um campo de ação carregado de tensões interpessoais; ansiedade em procurar formas de melhoria para a instituição; relação de afeto e desafeto com a instituição e insatisfação por considerar que os colegas de regime nem sempre valorizavam a instituição e não seguiam as regras institucionais.

Esses aspectos expressivos culminam em campos de ações divergentes e conflitivos, que não promovem a resolução dos conflitos no cotidiano da instituição. Assim, o participante permaneceu no CSS, mas reclamava das suas expectativas feridas quanto à instituição, ao mesmo tempo em que levava novas ideias e projetos para o setor administrativo e convivia com o distanciamento nas relações interpessoais. As divergências, entre os papéis sociais que ele gostaria de executar e os papéis institucionais, o colocavam em uma fronteira na qual havia limite para suas ações, fazendo emergir o sentido da APAC como algo bom para ele e sobre a qual ele não teria nada a reclamar, um posicionamento cristalizado diante da impossibilidade de mudança da realidade institucional vivenciada. Contudo, falar de suas opiniões, insatisfações e ideias ao setor administrativo e à pesquisadora aparecem, nos enunciados, como uma forma de se sentir útil e contribuir com a instituição. As tensões dialógicas permaneceram não resolvidas, e ele continuava cumprindo ora o papel determinado pela instituição, ora defendendo sua posição pessoal. Percebemos, então, uma passagem fluida entre duas posições distintas no contexto institucional, quando a pessoa se coloca pertencente a um ou outro grupo institucional, uma fronteira (Boesch, 1991), enquanto uma passagem permeável de um lugar a outro, ou de uma posição a outra.

\section{Os múltiplos campos de sentido nas relações intra e interpessoais articulados pela instituição APAC}

Os dados construídos a partir das entrevistas e do compartilhamento de situações extraverbais que emergiram durante as visitas periódicas à instituição remetem a uma relação dialógica entre as experiências das pessoas nos dois sistemas prisionais brasileiros, convencional e método APAC. Entre essas experiências das pessoas emergem relações que justificam a origem do método APAC enquanto proposta de assistência à pessoa presa e sua valoração a partir de uma ruptura com a ausência de cuidados quanto aos direitos da pessoa que cumpre pena privativa de liberdade. $\mathrm{O}$ sentido atribuído ao método APAC se articula à experiência prévia da pessoa no sistema prisional convencional.

O ambiente sociocultural das sanções penais é marcado por uma diversidade de valores pessoais e práticas compartilhadas e repetidas entre os grupos, que favorecem fortes assimetrias dialógicas a respeito das políticas de segurança pública, execução de penas e inserção social. As relações que as pessoas estabelecem com as sanções penais e com a prática de penitência devem incluir uma leitura histórico-cultural, pois as referências pessoais estético-afetivas proporcionadas e valorizadas pela cultura fomentam compreensões distintas da realidade a partir da socialização. Assim, os homens em aprisionamento no método APAC podem atribuir um sentido de que não estão cumprindo com o previsto para a pena, entendida a partir de seu caráter aflitivo, se não passarem por experiências de suplício ou penitência. Tais compreensões são internalizadas a partir do campo sociocultural, indicando os meios para se obter perdão pelos 
'erros' cometidos juridicamente ou pelos 'pecados' praticados contra outras pessoas, em uma atribuição de sentidos religiosos, uma forma de expiação dos pecados pelo sacrifício.

A antinomia entre estar na condição de um condenado e possuir tratamento digno fomenta conflitos intrapessoais. O dilema 'lidar com o caráter aflitivo da pena', se encaixa em dois subenquadramentos (Goffman, 1974; Moore, Jasper \& Gillespie, 2011) que se encontram em tensão para o Self, a saber, 'execução penal com dignidade' e o 'suplício relacionado à pena', que se dão no contexto da experiência institucionalizada.

No contexto interpessoal, outras antinomias se apresentam: cumprir pena no método APAC, embora favoreça a remição de pena devido às atividades laborterapêuticas e profissionalizantes, e implique receber visitas familiares sem revistas vexatórias, pode promover uma tensão com as pessoas do sistema prisional convencional, uma vez que precisa seguir disciplinas e delatar os colegas que as descumprem durante a pena. Esse convívio interpessoal conflitivo favorece a construção de processos afetivo-cognitivos estabelecidos e compartilhados na instituição penal APAC.

A pessoa pode construir uma visão de si mesma a partir de um mecanismo disciplinador, que sustenta o suplício como inerente a trajetória de vida, ao cumprir um preceito religioso de penitência. E a cultura, enquanto um campo dinâmico e balizador das ações simbólicas (Boesch, 1991), oportuniza ações simbólicas, mas também as interdita e coloca limites de tolerância, como transgressões ou novidades (Simão, 2010).

Existem duas experiências institucionais distintas, APAC e execução penal convencional, cada qual com seus sinais, direções e ritmos, bem como produções de estereótipos. Como exemplo, uma pessoa entrevistada narrou "que é um preso feliz no método APAC, o que não lhe ocorria no sistema convencional". A antinomia que se faz presente neste enunciado é estar preso versus ser um preso feliz, produzindo-se felicidade em um contexto de reclusão. $\mathrm{O}$ ambiente sociocultural favorece a apresentação de múltiplos caminhos possíveis para a pessoa, através da diversificação de repertórios pessoais e a partir das situações vivenciadas. As tensões surgem a partir da dificuldade de estabelecer uma organização coerente e plausível entre ambas as dimensões da experiência coletiva e subjetiva (Simão et al., 2015). Os pontos de vista acerca da execução das penas se constituem a partir da construção das narrativas em diferentes campos culturais (políticas públicas, instituições sociais, religiosas e de justiça, intervenções comunitárias, relações familiares), em uma multiplicação de trajetórias de produção de sentidos sobre o suplício e a aplicabilidade das penas.

Distintas perspectivas socioculturais permeiam a experiência de cumprimento de pena para a pessoa, de modo que a construção cultural do Self articula, de modo inclusivo, vivência institucionalizada. De um lado, temos a figura do Estado, enquanto governo de Minas Gerais, que investe e mantém a instituição APAC como política pública no Estado mineiro, em interface com os agentes públicos do Judiciário. Este último, é o órgão responsável pela aplicabilidade e cumprimento das penas através das Varas de Execução Penal deste e de outros estados brasileiros que contemplam a metodologia, e representa uma subseção do Governo do Estado, assim como o sistema prisional convencional a ele submisso. O Estado, Judiciário e Sistema Prisional Convencional, por meio de seus representantes, mantêm uma atuação conjunta e interdependente.

Também notamos a participação da FBAC enquanto um órgão fiscalizador das unidades APAC em todo o Brasil. A FBAC é formada por representantes do poder público, membros de ONGs e egressos do sistema prisional APAC, e media as negociações com o poder público local em cada Comarca, e com a sociedade civil organizada.

A sociedade civil organizada solicita a existência de uma instituição APAC via audiência pública e 
dela emerge, no mínimo, uma chapa contemplando cerca de 15 a 20 pessoas que tenham interesse em participar da APAC como diretoria, secretários e Conselho deliberativo da instituição. Para mediar as negociações e trocas dialógicas entre os membros institucionais quanto a emergência de novas unidades do método APAC e sua permanência na Comarca local é preciso lidar com fronteiras (Boesch, 1991) permeáveis que permitam um ir e vir entre perspectivas que conectem a experiência vivida na instituição aos aspectos interpessoais vivenciados no âmbito extra-instituição.

As pessoas que representam a FBAC (em conjunto com as pessoas da sociedade civil organizada) precisam se articular com a diretoria voluntária da instituição para negociar com as pessoas representantes da comunidade que envolve a APAC, uma nova fronteira que se coloca entre voluntariado $e$ comunidade envolvente.

As pessoas da comunidade envolvente, localizadas no entorno da unidade prisional APAC, a família, representantes das religiões que prestam assistência aos participantes da APAC, os líderes das oficinas e de processos educacionais e profissionalizantes, também, participam do método APAC. Produzem, assim, articulações difusas entre si, haja vista que a família está inserida na sociedade civil e na comunidade envolvente, nas quais se inclui em relações concretas normatizadas por um Estado, enquanto governo, e pela justiça penal, que, por sua vez, se interpelam aos sistemas prisionais que dão origem ao método APAC.

Assim, as dimensões institucionais diversas e difusas, presentes no campo social complexo, coparticipam de todas relações concretas que viabilizam negociações intra e intersubjetivas para a pessoa que cumpre pena. Essas dimensões viabilizam processos recursivos no fluxo da temporalidade que, portanto, podem se alternar, bem como interpelar uns aos outros e promover mudanças ou estabilidade nos processos administrativos que regulam a vida institucionalizada. Afinal, formas singulares de experimentar o curso dos eventos vividos se fazem presentes no desenvolvimento humano (Valsiner, 2007) a partir das experiências das pessoas, que carregam significados que articulam passado, presente e futuro.

As dimensões que se referem à família e à profissionalização sugerem dupla afetação, haja vista que são dois pilares da execução penal APAC no que se refere a favorecer a inserção social ${ }^{3}$ dos egressos desse sistema prisional. Uma dimensão potencializa ou dificulta a outra, o vínculo familiar pode favorecer o reingresso em atuações profissionais, e a profissionalização pode favorecer a manutenção financeira dessa família após o retorno do egresso à sociedade e a suspensão do benefício de auxílio reclusão aos seus dependentes, benefício concedido a pessoas que trabalhavam com carteira assinada antes da prisão.

Sobre o sistema convencional de execução penal, este emergiu nas falas dos participantes como uma perspectiva distinta da APAC, porém vinculada ao Judiciário. Entretanto, uma vez que no método APAC há somente pessoas julgadas e condenadas, esse sistema mantém fortes tensões dialógicas de relação com o sistema APAC, dada a divergência metodológica quanto a ausência de agentes armados e policiais, mas que se relaciona a ele, uma vez que a pessoa traz uma experiência preliminar com o sistema prisional convencional antes de adentrar à APAC. Existe uma fragilidade nas relações estabelecidas entre esses dois métodos de execução penal: o sistema convencional está descrito como subseção do Estado/governo, e a implantação do sistema APAC acaba criando um campo de tensões, uma vez que promove rupturas nos processos de cumprimento das medidas privativas de liberdade ao permitir uma relativa autonomia e participação ativa das pessoas que cumprem pena na administração dos processos e atividades institucionais. Notamos, então, que, no

A partir dos dados desta pesquisa não posso afirmar que seja reinserção social, haja vista que se trata de pessoas excluídas da sociedade. 
centro da experiência institucionalizada, encontra-se um campo nebuloso de trocas afetivas ${ }^{4}$ que se dão entre as diferentes posições que emergem para o Self no método APAC. Essas diferentes posições fazem emergir zonas de significados indeterminados, em disputa. O campo nebuloso de afetação fomenta as tensões dialógicas e angústias na busca por negociações de sentido, construções simbólicas e decisões concretas no âmbito relacional, pois se caracteriza como um emaranhado de possibilidades não claramente articuladas, a partir do qual os participantes constroem sentidos no campo institucional de execução penal.

Com base nos enunciados das entrevistas e nos dados extraverbais da pesquisa, constatamos que o governo do Estado de Minas Gerais, a partir da implantação do método APAC como política pública, incentiva as expansões das unidades APAC como forma de redução de custos, como tentativa de redução da reincidência ao crime e da superlotação dos presídios do Estado ('o preso como um custo’). Emergiu, na fala da operadora de direito entrevistada, que o Estado de Minas Gerais sugere aos Tribunais de Justiça o aumento do número de vagas nas APACs, mas acrescenta que é preciso melhorar as condições de segurança para atingir essa meta. Ou seja, existe uma pressão que impera sobre o Tribunal de Justiça para aumentar o número de vagas na metodologia APAC, e o Tribunal de Justiça cobra dos Juízes das Varas Criminais uma liberação destas vagas e um incentivo à metodologia. Entretanto, em algumas Comarcas em que a metodologia APAC se encontra em fase inicial de implantação, as unidades ainda têm espaço físico reduzido ou insuficiente para abrigar um maior número de pessoas.

O campo nebuloso diz respeito ao fluxo afetivo pré-semiótico da experiência na fronteira do Self, outro e do mundo (Valsiner, 2007).

\section{Considerações finais}

As tensões dialógicas que se dão na experiência institucionalizada da pessoa que cumpre pena no método APAC podem provocar um deslocamento das expectativas iniciais da pessoa quanto ao método, fomentar antinomias e conflitos entre sua posição pessoal e sua posição institucional ao assumir dupla função no método: cumprir a pena e coadministrar a instituição penal. Estas tensões, também, podem promover um campo nebuloso de afetos que podem atingir ou permear a própria metodologia, em que as pessoas em cumprimento de pena são afetadas por conflitos interpessoais, mas, para além de serem afetadas por eles, são elas, também, pessoas ativas e transformadoras da própria história de vida, capazes de um reposicionamento frente à sua trajetória de vida.

A partir da análise dos dados empiricamente construídos, observamos que o método APAC favorece a emergência do significado de 'um período de revisão de vida' para o cumprimento de pena, com base na proposta aí existente de assistência jurídica, à saúde, social, material e religiosa prevista na Lei de Execução Penal Brasileira. Verificamos que se trata de uma intervenção psicossocial que busca cumprir com os pressupostos previstos na Lei de Execução Penal (LEP) e que visa uma mudança no curso de vida de quem cumpre pena, fundamentada em preceitos religiosos do Cristianismo. Embora, também, promova assistência espiritual conforme a crença expressa por cada pessoa, sem se caracterizar como uma instituição religiosa, mas como uma política pública vinculada ao Tribunal de Justiça do Estado. Alguns princípios religiosos cristãos, como 'amor e misericórdia' aparecem implicitamente nas relações institucionais, que demonstram, nas relações estabelecidas entre funcionários/diretoria e pessoas em cumprimento de pena/familiares, o respeito e o entendimento que todas as pessoas podem 'errar' - do ponto de vista penal e, também, religioso-em alguma 
circunstância, mas elas não deixam de ser merecedoras de uma oportunidade para ressignificar sua trajetória de vida.

Constatamos, a partir dos dados empíricos, que a instituição APAC oferece uma oportunidade para ressignificar a trajetória de vida da pessoa que cumpre pena e construir novas expectativas para o futuro. Também significa uma oportunidade para buscar por uma inserção social a partir do fortalecimento ou resgate de vínculos familiares, e do convívio e participação da comunidade local na administração da própria instituição. Romper com o discurso autoritário e excludente da execução penal tradicional, tal como pressupõe o método APAC de execução penal, fomenta uma subversão ao sistema prisional ao abrir mão de escolta e agentes de segurança armada, e constitui um sistema aberto que permite uma coparticipação e coautoria daqueles que cumprem pena na administração e fiscalização da própria instituição penal APAC. O método, assim, evoca a autonomia e a liberdade como valores, como signos hipergeneralizados (Valsiner, 2012) na regulação semiótica afetiva.

Considerando que toda cognição de um fenômeno envolve a relação afeto-cognição (Guimarães, 2013), as cognições estão sempre vinculadas às percepções e às imaginações. Se a pessoa apresenta seus próprias afetos e cognições, não há como compreendê-la no contexto institucional sem nos colocarmos nesse mesmo contexto de diálogo e de experiências. Entendemos, ainda, que a dimensão extraverbal nas relações dialógicas é fundamental para a compreensão dos enunciados e da relação afeto-cognição que perpassa o fenômeno expresso pela pessoa. Constatamos que, para além dos muros das instituições penais, as pessoas compartilham significados da experiência com a sociedade, constituindo a cultura coletiva, e internalizam e significam tais aspectos na cultura pessoal. A experiência singular dessas pessoas extrapola as formas mais cristalizadas de um viver institucionalizado, mesmo em um contexto de execução penal.

\section{Referências}

Bastien, S. (2007). Observation participante ou participation observante? Usages et justifications de la notion de participation observante en sciences sociales. Université de Caen Basse-Normandie, 27(1), 127-140.

Boesch, E. E. (1991). Symbolic action theory and cultural psychology. Berlin- Heidelberg: Springer-Verlag.

Branco, A., \& Madureira, A. F. (2008). Dialogical Self in action: The emergence of self-positions among complex and cultural dimensions. Estudios de Psicología, 29(3), 319-332.

Ferreira, V. A. (2016). Juntando os cacos, resgatando vidas: valorização humana- base do método APAC e a viagem ao mundo do prisioneiro: $p$ sicologia do preso. Belo Horizonte: O Lutador.

Goffman, E. (1974). Frame analysis: An essay on the organisation of experience. New York: Harper and Row.

Guimarães, D. S., \& Simão, L. M. (2007). Intersubjetividade e desejo nas relações sociais: O caso dos jogos de representação de papéis. Interacções (Portugal), 3, 30-54.

Guimarães, D. S. (2013). Self and dialogical multiplication. Interacções, 24, 214-242.

Guimarães, D. S. (2016). Descending and ascending trajectories of dialogical analysis: Seventh analytic interpretation on the short story "The guerrillero". Psicologia USP, 27(2), 189-200. https://dx.doi.org/10.1590/01036564D20160003.

Hermans, H. J. M, Kempen, H. J. G., \& Van Loon, R. J. P. (1992). The dialogical self: Beyond individualism and rationalism. American Psychologist, 47, 23-33.

Malfitano, A. P. S., \& Marques, A. C. R. (2011). A entrevista como método de pesquisa com pessoas em situação de rua: questões de campo. Revista Cadernos de Terapia Ocupacional, Universidade Federal de São Carlos, 19(3), 289-296. 
Marková, I. (2003). Constitution of the self: Intersubjectivity and dialogicality. Culture \& Psychology, 9(3), 249-259.

Marková, I. (2006). Dialogicidade e representações sociais: as dinâmicas da mente. Petrópolis: Vozes.

Moore, H., Jasper, C., \& Gillespie, A. (2011). Moving between frames: The basis of the stable and dialogical self. Culture \& Psychology, 17(4), 510-519.

Ottoboni, M. (1997/2001). Ninguém é irrecuperável: $A P A C$, a revolução do sistema penitenciário. São Paulo: Editora Cidade Nova.

Rommetveit, R. (1979). On negative rationalism in scholarly studies of verbal communication and dynamics residuals in the construction of human intersubjectivity. In R. Rommetveit, \& R. Blakar (Orgs.), Studies of language, thought and verbal communication (pp. 147-161). Londres: Academic Press.

Simão, L. M. (1988/1989). Interação verbal e construção de conhecimento. (Tese de doutorado, Universidade de São Paulo, São Paulo, Brasil).

Simão, L. M. (2010). Ensaios dialógicos: compartilhamento e diferença nas relações eu-outro. São Paulo: Hucitec.

Simão, L. M. (2016). Culture as a moving symbolic borders. Integrative Psychological and Be- havioral Science, 50(1): 14-28. Doi: https:// doi.org/10.1007/s12124-015-9322-6

Simão, L. M., Guimarães, D. S., Freitas, D. F., Bastos, S., \& Sanchéz, H. (2015). Researcher-participant relationships in different settings: Theoretical and methodological issues within the framework of semiotic-cultural constructivism. In M. Watzlawik, A. Kriebel \& J. Valsiner (Orgs.), Particulars and universals in clinical and developmental psychology: Critical reflections, a book honoring Roger Bibace (pp. 247-269). Charlotte, NC: Information Age Publishing.

Spink, P. K. (2003). Pesquisa de campo em psicologia social: uma perspectiva pós-construtivista. Psicologia \& Sociedade, 15(2), 18-42.

Valsiner J. (2007). Culture in minds and societies. Foundations of cultural psychology. New Delhi: Sage.

Valsiner, J. (2012). Fundamentos da psicologia cultural: mundos da mente, mundos da vida. Porto Alegre: Artmed.

Wertsch, J. V. (1993). Voices of the mind: A sociocultural approach to mediated action. Cambridge: Harvard University Press.

Zittoun, T. (2006) Transitions. Charlotte, NC: Information Age Publishing.

\section{Recebido: maio 9, 2019 Aprovado: agosto 6, 2019}


